\title{
Selection of culture conditions for callus induction and proliferation by somatic embryogenesis of Pinus koraiensis
}

\author{
Fang Gao ${ }^{1}$ Chunxue Peng ${ }^{1}$ Hao Wang ${ }^{1} \cdot$ \\ Hailong Shen ${ }^{1} \cdot$ Ling Yang ${ }^{1}$
}

Received: 4 November 2019 / Accepted: 13 December 2019 / Published online: 20 May 2020

(C) The Author(s) 2020

\begin{abstract}
The induction and proliferation of embryogenic callus are key steps for large-scale propagation of somatic embryogenesis pathway and long-term preservation of coniferous germplasm. Callus can be induced from immature embryos of Korean pine (Pinus koraiensis Sieb. et Zucc.; Pinaceae) as explants, but there are problems, such as low proliferation efficiency, loss of embryogenicity, poor vigor; thus, best conditions for proliferation and culture of immature embryos of Korean pine are not yet clear. To solve the problems with somatic embryogenesis of Korean pine and determine the best culture conditions for callus induction and proliferation, we varied hormone concentration, subculture cycle of proliferation and other plant growth regulators combinations in media to induce callus formation by megagametophytes of three Korean pine families at different developmental stages, then analyzed the effects on embryogenic callus retention and cell proliferation using a quadratic regression orthogonal rotation design. The results showed that the family origin and collection date of explants
\end{abstract}

Project funding: The work was supported by the National Key R\&D Program of China (2017YFD0600600).

The online version is available at http://www.springerlink.com

Corresponding editor: Tao $\mathrm{Xu}$.

Fang Gao and Chunxue Peng have are equal to this work.

Hailong Shen

shenhl-cf@nefu.edu.cn

Ling Yang

yangl-cf@nefu.edu.cn

1 State Key Laboratory of Tree Genetics and Breeding, School of Forestry, Northeast Forestry University, Harbin 150040, People's Republic of China significantly affected callus induction (induction rate reached $1.67 \%$ ). Embryogenic maintenance and callus proliferation were best on DCR medium supplemented with $0.25 \mathrm{mg} \mathrm{L}^{-1}$ 6-benzyl adenine, $1 \mathrm{mg} \mathrm{L}^{-1}$ naphthaleneacetic acid, $30 \mathrm{~g} \mathrm{~L}^{-1}$ sucrose, $500 \mathrm{mg} \mathrm{L}^{-1}$, L-glutamine, $500 \mathrm{mg} \mathrm{L}^{-1}$ casein hydrolysis and $6.5 \mathrm{~g} \mathrm{~L}^{-1}$ agar. In addition, the combination of 2,4-dichlorophenoxyacetic acid + 6-benzyl adenine also had a better proliferative effect on callus. The effects of different combinations of growth regulators on callus proliferation efficiency were significantly different. Transfer to new medium every 13-15 days not only maintained robust callus vigor, but also yielded a larger proliferation coefficient. The techniques and conditions for embryogenic callus induction and proliferation of Korean determined here will serve as a foundation for establishing a large-scale system for somatic embryogenesis and propagation of Korean pine.

Keywords Korean pine - Somatic embryogenesis . Embryogenic callus $\cdot$ Megagametophytes $\cdot$ Embryonic maintenance

\section{Introduction}

Somatic embryogenesis has become the main mode for vegetative reproduction because somatic embryos develop both apical meristem and root meristems (Lelu-Walter et al. 2018). Embryogenic callus is the foundation of regenerating plants on a large scale and serves as important material of genetic transformation, it also is an ideal system for studying the entirety of single-cell differentiation and the expression of totipotency (Zeng et al. 2007; Yang and Zhang 2010; Santa-Catarina et al. 2012; Steiner et al. 2016). For breeding, the use of somatic embryogenesis and the 
cryopreservation of embryogenic callus enables large-scale propagation of excellent seed resources (Lelu-Walter et al. 2013; Tret'yakova and Shuvaev 2015; Ahn et al. 2017). For this reason, obtaining a sufficient supply of high quality callus is a critical step for somatic embryogenesis. The main factors affecting the maintenance and proliferation of embryonic callus include the nutrient and hormonal composition of the medium, growth temperature and humidity, subculture cycle and genetic background of the embryonic callus. A combination of auxin and cytokinin is usually used for embryonic callus maintenance and proliferation of conifer species (Zuzana et al. 2011; Klimaszewska et al. 2016; Nunes et al. 2018).

Only a few studies have focused on tissue cultivation of Korean pine (Pinus koraiensis Sieb. et Zucc.), an important species for oil, nuts and high-quality timber (Liang et al. 2016). Shen et al. (2005) regenerated Korean pine plantlets via somatic embryogenesis, and Cao et al. (2009) determined the best explant type for callus induction from mature seeds, Wang et al. (2015) determined a suitable medium for embryogenic callus induction from a mature embryo, and Gao et al. (2017) determined suitable conditions for callus induction from different parts of mature seeds. However, in all these studies, callus induced from mature embryos had no embryogenicity or low embryogenic ability and could not be cultured for proliferation (Cao et al. 2009; Wang et al. 2015; Gao et al. 2017). Thus, problems such as low proliferation efficiency, unreliable embryogenicity, short retention time and poor vigor have been a constraint.

In the present study, megagametophytes from different developmental stages and families of $P$. koraiensis were tested to develop an efficient system for embryogenic callus maintenance and proliferation by altering plant growth regulator concentrations and combinations, subculture period, and clone origin on embryogenic callus initiation and proliferation and analyzing the effects with a quadratic regression orthogonal rotation design. Our findings lay a foundation for the development of a somatic embryogenesis technology system for large-scale propagation of Korean pine.

\section{Materials and methods}

\section{Preparation of materials}

Open-pollinated cones from three families (WH57, WH59, WH35) were collected in Qingshan Forest Seed Orchard of Weihe Forestry Bureau in Heilongjiang Province from July to September 2014 (July 1, July 7 July 14, July 21, July 28, August 4 and September 30). Cones (Fig. 1a) were washed with detergent for about $30 \mathrm{~min}$, then flushed under running water for $8 \mathrm{~h}$. After seed scales were removed, the seeds were treated with $75 \%$ alcohol on a clean bench for 1 to $2 \mathrm{~min}$, and flushed with sterile water five times. Seeds were then treated with $10 \%$ v/v sodium hypochlorite solution for $15 \mathrm{~min}$, and flushed with sterile water five times. The seed coat was the removed, and the megagametophytes were treated with $3 \% \mathrm{v} / \mathrm{v}$ hydrogen peroxide for $8 \mathrm{~min}$, and flushed with sterile water five times. The megagametophytes were then used as explants, and their developmental state was determined with a microscope (OLYMPUS SZX7, Japan) before use in tissue culture.

\section{Callus induction}

The initiation medium for embryogenic callus induction consisted of Douglas-fir cotyledon revised medium (DCR) + agar $6.5 \mathrm{~g} \mathrm{~L} \mathrm{~L}^{-1}+\mathrm{L}$-glutamine $500 \mathrm{mg} \mathrm{L}^{-1}+$ sucrose $30 \mathrm{~g} \mathrm{~L}^{-1}+$ naphthaleneacetic acid [NAA] $2 \mathrm{mg} \mathrm{L}^{-1}+6$-benzyl adenine [6-BA] $1 \mathrm{mg} \mathrm{L}^{-1}+$ casein hydrolysate $0.5 \mathrm{~g} \mathrm{~L}^{-1}$ ( $\mathrm{pH}$ adjusted to 5.8 with $\mathrm{NaOH}$ or $\mathrm{HCl}$ before autoclaving). Five megagametophyte explants from each origin were placed on each of 15 dishes of medium, Cells were then placed in the dark at $24 \pm 1{ }^{\circ} \mathrm{C}$ for 2 months to obtain embryogenic callus.
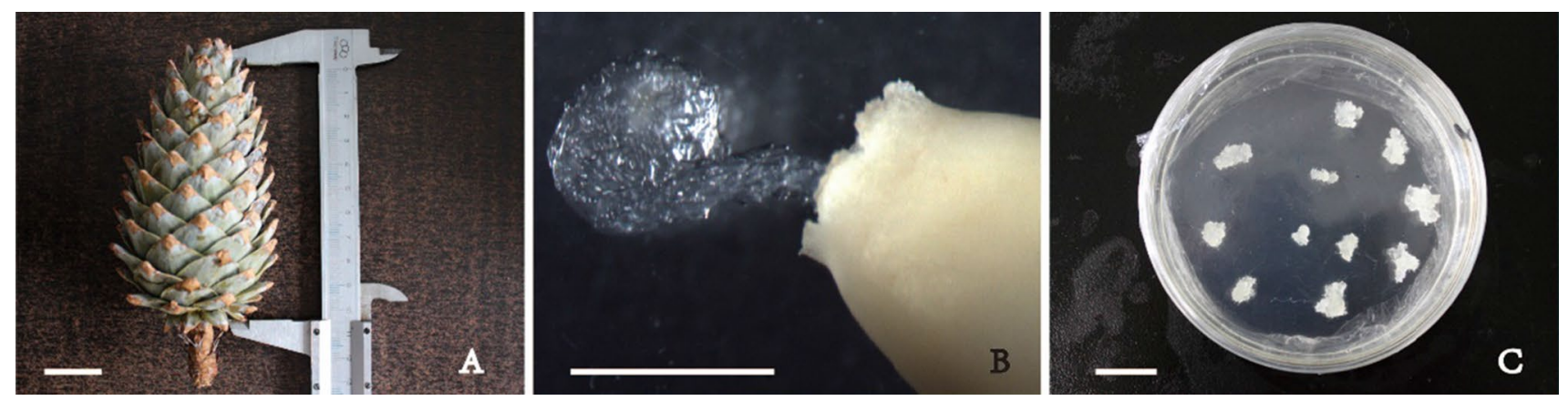

Fig. 1 Callus induction and proliferation of Korean pine. a Immature cone. $\mathbf{b}$ Callus growing from explants. $\mathbf{c}$ Callus proliferation. Bars $=4 \mathrm{~cm}$ (a); $1 \mathrm{~cm}(\mathbf{b}, \mathbf{c})$ 


\section{Callus proliferation}

\section{Screening of proliferation medium components}

Experiment 1 A three-factor quadratic regression orthogonal rotation design was applied for studying the effects of hormones (NAA, 6-BA and kinetin [KT]) on embryogenic callus maintenance and proliferation of clone WH59-1 of $P$. koraiensis. Table 1 shows the concentration of hormones at the different levels for the quadratic regression orthogonal rotation design.

The medium for proliferation of embryogenic callus with the range of hormonal concentrations tested was $\mathrm{DCR}+6$-BA $\left(0-0.5 \mathrm{mg} \mathrm{L}^{-1}\right)+\mathrm{KT}\left(0-0.5 \mathrm{mg} \mathrm{L}^{-1}\right)+\mathrm{NAA}$ $\left(0-2 \mathrm{mg} \mathrm{L}^{-1}\right)+\mathrm{L}$-glutamine $500 \mathrm{mg} \mathrm{L}^{-1}+$ casein hydrolysate $500 \mathrm{mg} \mathrm{L}^{-1}+$ agar $6.5 \mathrm{~g} \mathrm{~L}^{-1}+$ sucrose $30 \mathrm{~g} \mathrm{~L}^{-1}$ (pH was adjusted to 5.8 with $\mathrm{NaOH}$ or $\mathrm{HCl}$ before autoclaving). Each of four replicate dishes per treatment received $0.2 \mathrm{~g}$ callus, then all dishes were placed in the dark at $24 \pm 1{ }^{\circ} \mathrm{C}$ for $17 \mathrm{~d}$. The embryonic cell in each dish were then weighed, growth rate of embryonic callus was calculated, and then the best mass concentration of the plant growth regulators (PGRs) for embryogenic callus proliferation was determined for Experiment 2.

Experiment 2 For analyzing the effect of different combinations of hormones on embryogenic callus maintenance and proliferation of clone WH35-1, $0.2 \mathrm{~g}$ embryonic callus clusters were cultured on DCR medium with five combinations and concentrations of different PGRs: Treatment 1, 2,4-Dichlorophenoxyacetic acid [2,4-D] $0.5 \mathrm{mg} \mathrm{L}^{-1}+6-\mathrm{BA} 0.12 \mathrm{mg} \mathrm{L}^{-1}$; Treatment 2, indolebutyric acid (IBA) $0.5 \mathrm{mg} \mathrm{L}^{-1}+6-\mathrm{BA}$ $0.12 \mathrm{mg} \mathrm{L}^{-1}$; Treatment 3, IBA $0.5 \mathrm{mg} \mathrm{L}^{-1}+$ abscisic acid (ABA) $1.0 \mathrm{mg} \mathrm{L}^{-1}$; Treatment 4, 6-BA $0.12 \mathrm{mg} \mathrm{L}^{-1}+\mathrm{KT}$ $0.05 \mathrm{mg} \mathrm{L}^{-1}$; Treatment 5 , 2,4-D $0.5 \mathrm{mg} \mathrm{L}^{-1}+\mathrm{ABA}$ $1.0 \mathrm{mg} \mathrm{L}^{-1}$. The rest of the conditions were the same as described for this paper's Experiment 1, but with three dishes per treatment. After 15 days, each callus was weighed, and the proliferation efficiency of the callus determined.

\section{Determination of the healing cycle of callus proliferation}

Vigorously growing callus ( $0.2 \mathrm{~g})$ of WH35-1 was placed on the optimal proliferation medium (the same as this paper's Experiment 1), in each of five dishes per treatment. Growth state and mass of embryogenic callus was recorded every other day, then the increase in mass for each embryogenic callus was determined, and a growth curve was drawn to determine the best proliferation subculture cycle.

\section{Characteristics of callus proliferation of different cell lines}

The transparent or milky embryogenic cell lines (e.g. WH57-1, WH59-1 and WH35-1) with a diameter of 1-2 cm was transferred from the induction medium to the proliferation medium. About $0.5 \mathrm{~g}$ of embryogenic callus were cultured on the optimal medium (the same as this paper's Experiment 1) with four clusters of embryogenic callus per dish and three replications per clone. The cultures were placed in the dark at $24 \pm 1{ }^{\circ} \mathrm{C}$ for 15 days. Proliferation efficiency, callus mass and growth status of each embryonic callus were then determined.

\section{Data analyses}

All experimental data were recorded in Excel 2003 to calculate means and growth rate for treatments. SPSS 19 (IBM, Armonk, NY, USA) was used to analyze variance and the significance of differences in the percentage of callus induction. Two-factor variance analysis, regression analysis and $\mathrm{F}$ test were used to analyze callus proliferation efficiency. The data was inversely sinusoidal square root transformed before analysis. Callus proliferation curves were drawn using Sigma Plot 12.5 (Systat, Chicago, IL, USA).

Callus induction (\%)

$$
=\frac{\text { Number of explants producing callus }}{\text { Number of surviving explants inoculated }} \times 100 \%
$$

Proliferation efficiency (\%)

$=\underline{\text { Fresh mass of callus after culture }- \text { Fresh mass of callus before culture }}$

$=\frac{\text { Fresh mass of callus before culture }}{}$

$\times 100 \%$

Table 1 Factor coding of quadratic orthogonal rotation combination design

\begin{tabular}{llll}
\hline Level & $X_{1} / \mathrm{NAA}$ & $X_{2} / 6-\mathrm{BA}$ & $X_{3} / \mathrm{KT}$ \\
\hline 1.682 & 2 & 0.5 & 0.5 \\
1 & 1.5945 & 0.3986 & 0.3986 \\
0 & 1 & 0.25 & 0.25 \\
-1 & 0.4055 & 0.1014 & 0.1014 \\
-1.682 & 0 & 0 & 0 \\
$\Delta \mathrm{j}$ & 0.5945 & 0.1486 & 0.1486 \\
\hline
\end{tabular}

The first column is the level coding of experimental factors; the last three are concentration values of NAA, 6-BA and KT under each level. Charling quadratic general rotation design parameter table obtains an asterisk arm of 1.682 


\section{Results}

\section{Effect of explant maturity on callus induction}

The developmental status of megagametophytes in each collection period is shown in Table 2. As collection times were delayed, the physiological maturity of megagametophytes gradually increased. The explants were inoculated on the callus induction medium for about 30 days, and callus was ejected from the micropyle end (Fig. 1b). Callus induction rate differed significantly among explant collection times (Table 3). For the different families, callus was induced on megagametophytes collected on only first two of the seven collection dates (July 1 and 7); from July 14 to September 30 , the induction rate was 0 . The callus induction rate of explants in the proembryonic stage (July 1) was significantly higher than that for tissue collected on July 7. For July 1 and July 7 , the order of callus induction rate of the three families was WH35>WH59> WH57. When the callus grew to 1-3 cm, it was transferred to proliferation medium (Fig. 1c).

Table 2 Development status of megagametophytes and zygotic embryo of Korean pine collected on different dates

\begin{tabular}{|c|c|c|c|}
\hline Date & Seed development & Embryo development & Seed state \\
\hline July 1 & $\begin{array}{c}\text { E1 } \\
\text { Early embrygeny }\end{array}$ & - & \\
\hline July 7 & $\begin{array}{c}\text { E2 } \\
\text { Early embrygeny }\end{array}$ & - & \\
\hline July 14 & $\begin{array}{c}\text { E3 } \\
\text { Early embrygeny }\end{array}$ & & \\
\hline July 21 & $\begin{array}{c}\text { E4 } \\
\text { Late embrygeny }\end{array}$ & & \\
\hline July 28 & $\begin{array}{c}\text { E5 } \\
\text { Late embrygeny }\end{array}$ & & \\
\hline August 4 & $\begin{array}{c}\text { E6 } \\
\text { mature embryogeny }\end{array}$ & & \\
\hline September 30 & $\begin{array}{c}\text { E7 } \\
\text { mature embryogeny }\end{array}$ & & \\
\hline
\end{tabular}

Bars $=0.2 \mathrm{~cm}$ 
Table 3 Effect of maturity level of explants for three families of Korean pine on embryogenic callus induction

Collection date Average induction percentage of embryogenic callus $(\%)$

\begin{tabular}{llll} 
& WH57 & WH59 & WH35 \\
\hline July 1 & $1.08 \pm 0.29 \mathrm{aC}$ & $1.33 \pm 0.31 \mathrm{aB}$ & $1.67 \pm 0.23 \mathrm{aA}$ \\
July 7 & $0.75 \pm 0.18 \mathrm{bC}$ & $1.00 \pm 0.11 \mathrm{bB}$ & $1.20 \pm 0.16 \mathrm{bA}$ \\
\hline
\end{tabular}

Different letters in the same column indicate significant difference among maturity (collection date) of a particular clone at $\alpha=0.05$; different capital letters in the same row indicate significant difference among families at $\alpha=0.05$

\section{Effects of NAA, 6-BA and KT on callus proliferation}

Table 4 shows the programs and results of the quadratic regression orthogonal rotation combination test design for three factors, the regression coefficients and mathematical regression model of the three factors encoded value for NAA, 6-BA and KT. Significance of regression coefficients, regression equation and lack of fit of regression model was tested using $F$ tests.
Significance test of the regression equation (RE) $F_{\mathrm{RE}}=5.557>F_{0.05}(9,13)=2.71$ indicated a good fit between the predicted value of the regression model and the actual value. Significant regression coefficients were tested. After removal of the nonsignificant item at $\alpha=0.05$, an optimized regression equation was obtained as $y=131.762+106.866$ $x_{1}^{2}+213.732 x_{1}-62.626 x_{2}^{2}+31.313 x_{2}-32.051 x_{3}$. The sequence of the factors that affected proliferation of embryogenic callus was NAA (0.256) > 6-BA (0.116) $>$ KT $(-0.060)$, and NAA and 6-BA were positively correlated with callus proliferation rate, while KT was negatively correlated with callus proliferation rate.

The test of lack of fit of regression equation indicated that the equation was not lack of fit $(F=1.0783<F(5,8)=3.68$, Table 3). The highest proliferation rate was $y=242.543$, when $x_{1}=1, x_{2}=0.25, x_{3}=0$, according to the extreme value theory. Therefore, the most suitable medium for embryogenic callus maintenance and proliferation of $P$. koraiensis was DCR + $0.25 \mathrm{mg} \mathrm{L}^{-1} 6-\mathrm{BA}+1 \mathrm{mg} \mathrm{L}^{-1} \mathrm{NAA}+30 \mathrm{mg} \mathrm{L}^{-1}$ sucrose $+500 \mathrm{mg} \mathrm{L}^{-1} \mathrm{~L}$-glutamine $+500 \mathrm{mg} \mathrm{L}^{-1}$ casein hydrolysate $+6.5 \mathrm{~g} \mathrm{~L}^{-1}$ Agar.

Table 4 Test program and results of three-factor quadratic regression orthogonal design

\begin{tabular}{|c|c|c|c|c|c|c|c|c|c|c|c|}
\hline Test no. & $Z_{0}$ & $Z_{1}$ & $Z_{2}$ & $Z_{3}$ & $Z_{1} Z_{2}$ & $Z_{1} Z_{3}$ & $Z_{2} Z_{3}$ & $Z_{1}^{\prime}$ & $Z_{2}^{\prime}$ & $Z_{3}^{\prime}$ & $\begin{array}{l}\text { Mean apprecia- } \\
\text { tion percentage }\end{array}$ \\
\hline 1 & 1 & 1 & 1 & 1 & 1 & 1 & 1 & 0.406 & 0.406 & 0.406 & $111.81 \pm 9.47$ \\
\hline 2 & 1 & 1 & 1 & -1 & 1 & -1 & -1 & 0.406 & 0.406 & 0.406 & $222.71 \pm 23.73$ \\
\hline 3 & 1 & 1 & -1 & 1 & -1 & 1 & -1 & 0.406 & 0.406 & 0.406 & $144.85 \pm 28.27$ \\
\hline 4 & 1 & 1 & -1 & -1 & -1 & -1 & 1 & 0.406 & 0.406 & 0.406 & $129.11 \pm 20.12$ \\
\hline 5 & 1 & -1 & 1 & 1 & -1 & -1 & 1 & 0.406 & 0.406 & 0.406 & $192.50 \pm 7.77$ \\
\hline 6 & 1 & -1 & 1 & -1 & -1 & 1 & -1 & 0.406 & 0.406 & 0.406 & $201.43 \pm 12.87$ \\
\hline 7 & 1 & -1 & -1 & 1 & 1 & -1 & -1 & 0.406 & 0.406 & 0.406 & $200.80 \pm 22.27$ \\
\hline 8 & 1 & -1 & -1 & -1 & 1 & 1 & 1 & 0.406 & 0.406 & 0.406 & $170.00 \pm 5.40$ \\
\hline 9 & 1 & 1.682 & 0 & 0 & 0 & 0 & 0 & 2.234 & -0.594 & -0.594 & $93.66 \pm 16.31$ \\
\hline 10 & 1 & -1.682 & 0 & 0 & 0 & 0 & 0 & 2.234 & -0.594 & -0.594 & $137.50 \pm 1.44$ \\
\hline 11 & 1 & 0 & 1.682 & 0 & 0 & 0 & 0 & -0.594 & 2.234 & -0.594 & $165.00 \pm 6.12$ \\
\hline 12 & 1 & 0 & -1.682 & 0 & 0 & 0 & 0 & -0.594 & 2.234 & -0.594 & $153.33 \pm 29.02$ \\
\hline 13 & 1 & 0 & 0 & 1.682 & 0 & 0 & 0 & -0.594 & -0.594 & 2.234 & $127.50 \pm 5.20$ \\
\hline 14 & 1 & 0 & 0 & -1.682 & 0 & 0 & 0 & -0.594 & -0.594 & 2.234 & $237.50 \pm 12.99$ \\
\hline 15 & 1 & 0 & 0 & 0 & 0 & 0 & 0 & -0.594 & -0.594 & -0.594 & $218.33 \pm 56.74$ \\
\hline 16 & 1 & 0 & 0 & 0 & 0 & 0 & 0 & -0.594 & -0.594 & -0.594 & $301.67 \pm 8.33$ \\
\hline 17 & 1 & 0 & 0 & 0 & 0 & 0 & 0 & -0.594 & -0.594 & -0.594 & $221.76 \pm 1.67$ \\
\hline 18 & 1 & 0 & 0 & 0 & 0 & 0 & 0 & -0.594 & -0.594 & -0.594 & $211.67 \pm 52.39$ \\
\hline 19 & 1 & 0 & 0 & 0 & 0 & 0 & 0 & -0.594 & -0.594 & -0.594 & $213.75 \pm 18.64$ \\
\hline 20 & 1 & 0 & 0 & 0 & 0 & 0 & 0 & -0.594 & -0.594 & -0.594 & $258.33 \pm 4.41$ \\
\hline 21 & 1 & 0 & 0 & 0 & 0 & 0 & 0 & -0.594 & -0.594 & -0.594 & $236.67 \pm 20.48$ \\
\hline 22 & 1 & 0 & 0 & 0 & 0 & 0 & 0 & -0.594 & -0.594 & -0.594 & $245.00 \pm 7.64$ \\
\hline 23 & 1 & 0 & 0 & 0 & 0 & 0 & 0 & -0.594 & -0.594 & -0.594 & $208.33 \pm 19.65$ \\
\hline
\end{tabular}

$Z j$ represents the no normative variable of its corresponding experimental factor $X j$ 


\section{Effects of 2,4-D, IBA and ABA on callus proliferation}

The embryogenic callus proliferated in all treatment; however, the effects of different combinations of PGRs on embryogenic callus proliferation differed significantly, except for that between IBA + ABA and 2,4-D + ABA (Table 5). Embryogenic callus grew fast and well on the media contained 2,4-D +6-BA, and the transparent, filamentous callus had more early somatic embryos on the surface (Fig. 2a) and retained embryonic features after repeated subcultures. In the combination of IBA +6-BA, the callus proliferated quickly, but it browned readily (Fig. 2b). Athough the callus proliferated after the browned part was removed and the subculture was continued, the callus structure was loose, yellow and continued to brown, and its embryogenicity was lost after 3-4 consecutive passages. Under IBA + ABA, the callus had low proliferation efficiency $(254.02 \%)$ and readily browned (Fig. 2c).

\section{Determination of embryonic callus subculture cycle}

The growth curve of embryogenic callus is shown in Fig. 4. The callus grew slowly after 1-3 days of culture. Embryogenic callus grew rapidly after 7 days (Fig. 3a); the growth rate was the fastest at 13-15 days, and the embryogenic callus had grown well thus far (Fig. 3b). By 20 days, the interior of the embryogenic callus had begun to brown and brown spots were present (Fig. 3c). After 25 days, the proliferation rate began to slow. During the proliferation process, the callus gradually turned yellow, from transparent to translucent, and the number of early somatic embryos of surface began to decrease, and the degree of browning continuously intensified (Fig. 3d). At 30 days, the callus was light yellow (Fig. 3e); by 35 days, the callus had lost its embryogenicity, turned yellow, and the internal browning was more serious (Fig. 3f). At this time, the browned part of the callus was removed and subculturing continued; the callus still had proliferative ability (Fig. 4), but its embryogenicity was gradually lost.

\section{Embryogenic callus preservation and proliferation of different cell lines}

Proliferation capacity of different cell lines differed significantly (Table $6 ; p<0.05$ ). The proliferation capacity of clone WH57-1 was the weakest, and the average proliferation efficiency were $105.18 \%$. During proliferation, the callus surface was pale yellow, and it gradually browned and hardened (Fig. 5a), and after 3 subcultures, the callus had browned intensely and lost its embryogenicity. Clone
Table 5 Effects of different combinations of hormones on embryonic callus maintenance and proliferation of Korean pine

\begin{tabular}{|c|c|c|c|}
\hline Treatment & PGRs materials & Proliferation efficiency $(\%)$ & Growth status of embryonic callus \\
\hline 1 & $2,4-\mathrm{D}+6-\mathrm{BA}$ & $405.46 \pm 12.12 b$ & $\begin{array}{l}\text { Proliferated fast, embryonic feature could } \\
\text { be maintained for a long term }\end{array}$ \\
\hline 2 & $\mathrm{IBA}+6-\mathrm{BA}$ & $398.39 \pm 20.93 c$ & $\begin{array}{l}\text { Proliferated fast, embryonic feature not be } \\
\text { maintained over long term }\end{array}$ \\
\hline 3 & $\mathrm{IBA}+\mathrm{ABA}$ & $253.25 \pm 10.30 \mathrm{~d}$ & Proliferated slowly and commonly browned \\
\hline 4 & $6-\mathrm{BA}+\mathrm{KT}$ & $414.49 \pm 18.17 \mathrm{a}$ & Proliferated fast and browned severely \\
\hline 5 & $2,4-\mathrm{D}+\mathrm{ABA}$ & $254.02 \pm 22.51 \mathrm{~d}$ & Proliferated slowly and browned severely \\
\hline
\end{tabular}

Different letters in the same column indicate a significant difference at $\alpha=0.05$
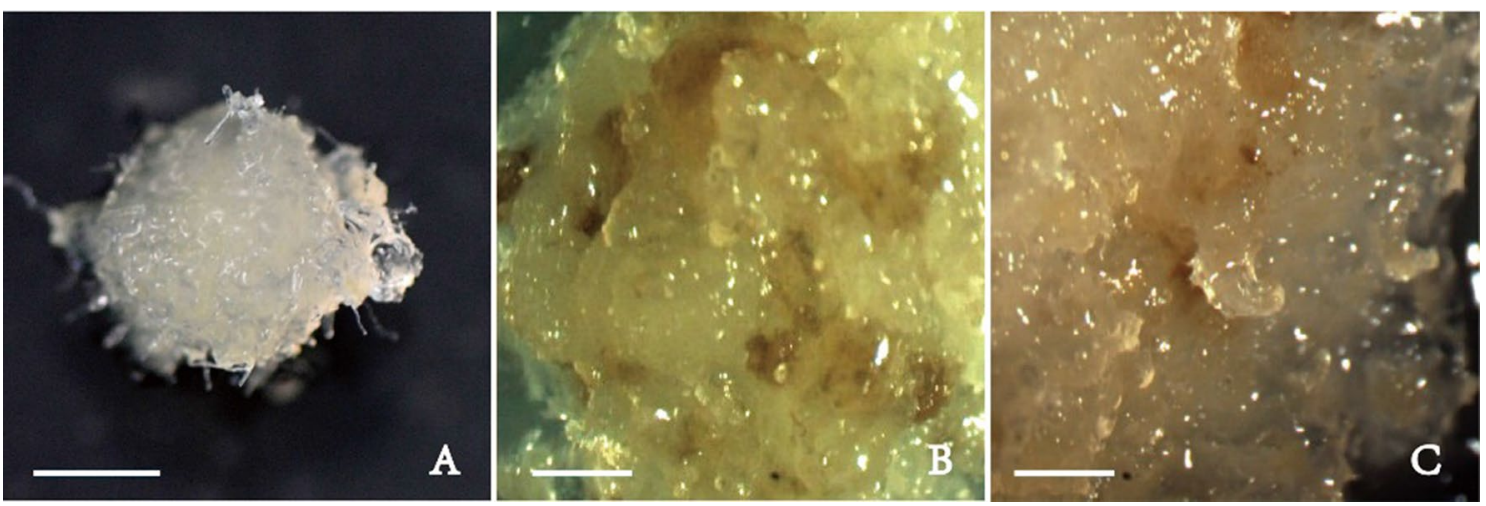

Fig. 2 Callus of Korean pine on different combinations of PGRs in medium after 15 days. a 2,4-D+6-BA. b IBA+6-BA. c IBA+ABA. Bars $=5 \mathrm{~mm}(\mathbf{a}) ; 1 \mathrm{~mm}(\mathbf{b}, \mathbf{c})$ 

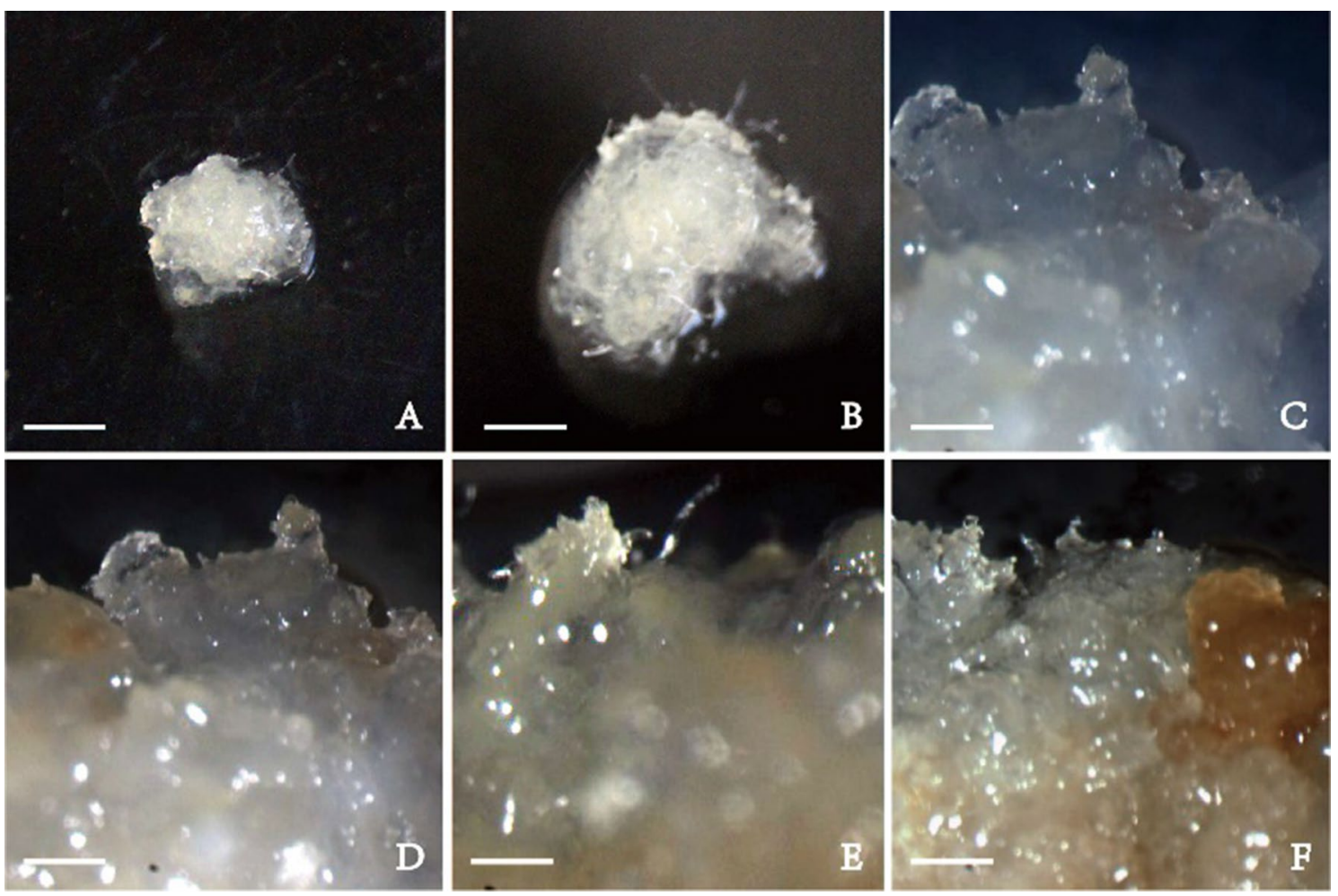

Fig. 3 Growth state of embryogenic callus of Korean pine on DCR medium during proliferation after a 7 days, b 15 days, $\mathbf{c} 20$ day, $\mathbf{d} 25$ days, e 30 days, and $\mathbf{f} 35$ days. Bars $=4 \mathrm{~mm}(\mathbf{a}, \mathbf{b}) ; 1 \mathrm{~mm}(\mathbf{c}-\mathbf{f})$

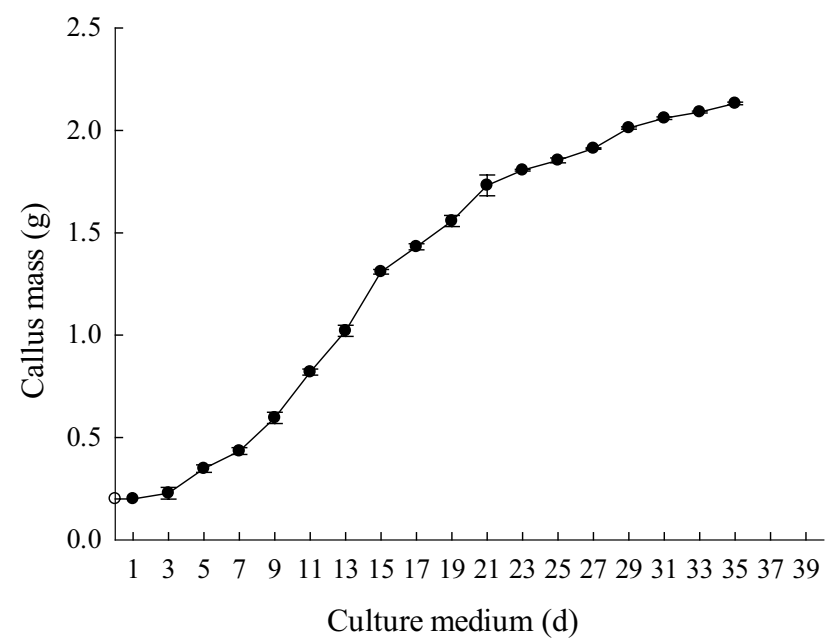

Fig. 4 Growth curves of embryogenic callus of Korean pine
WH59-1 proliferated rapidly, with average proliferation efficiency of $381.95 \%$ (Fig. 5b); clone WH35-1 had the fastest growth rate, with average proliferation efficiency of $474.97 \%$, and the callus grew well numerous filamentous early pro-embryos on its surface. Clone WH35-1 maintained its embryogenicity without browning over the long-term (Fig. 5c).

\section{Discussion and conclusion}

As the age and physiological status of the mother tree increases, the callus induction rate decreases significantly (Klimaszewska et al. 2016; Trontin et al. 2016; Salaj et al. 2015). Mother trees also differ significantly in the callus induction rate (Niskanen et al. 2004; Humánez et al. 2013). In our preliminary screening of suitable conditions
Table 6 Characteristics of cell lines maintenance and proliferation of Korean pin

\begin{tabular}{llll}
\hline Treatment & Number of cell lines & Proliferation efficiency (\%) & Growth status \\
\hline 1 & WH57-1 & $105.18 \pm 19.50 \mathrm{c}$ & Proliferated slowly and browned severely \\
2 & WH59-1 & $381.95 \pm 35.08 \mathrm{~b}$ & Proliferated faster and grew well \\
3 & WH35-1 & $474.97 \pm 1.041 \mathrm{a}$ & Proliferated fastest and grew well \\
\hline
\end{tabular}

Different letters in the same column indicate a significant difference at $\alpha=0.05$ 

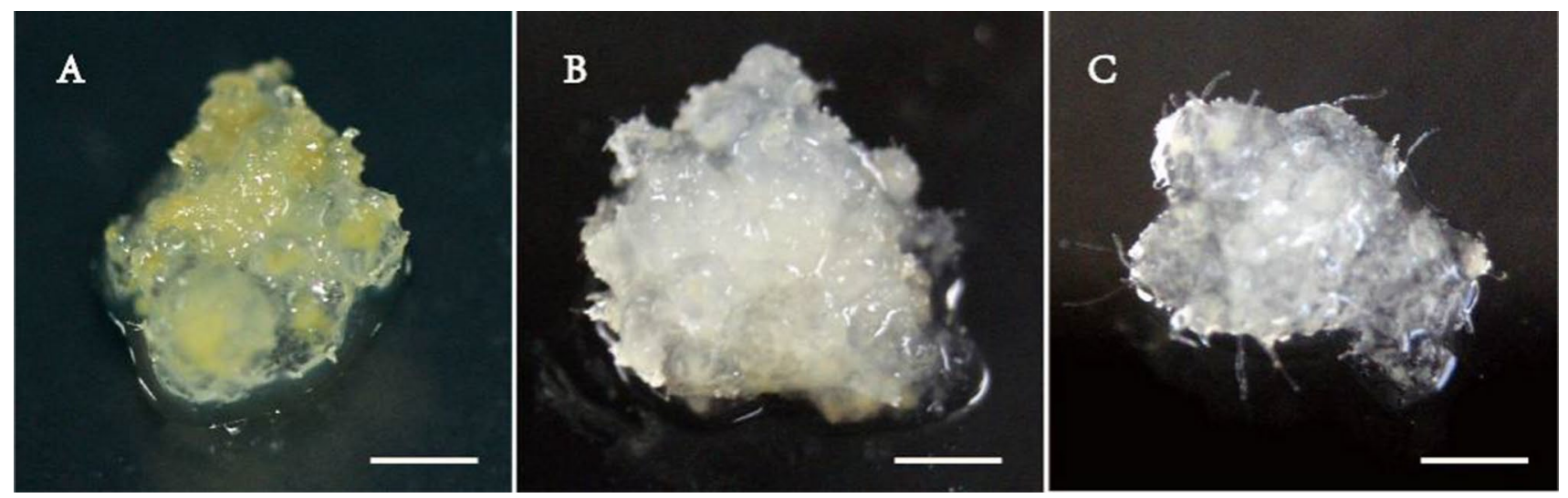

Fig. 5 Three cell lines of Korean pine embryogenic callus were cultured on DCR medium for 15 days. Clone a WH57-1, b WH59-1, c WH351. Bars $=0.5 \mathrm{~cm}(\mathbf{a}-\mathbf{c})$

for embryogenic callus induction of $P$. koraiensis, with increasing maturity of explants, the average induction rate of embryogenic callus differed. Different families differed significantly in the callus induction rate; WH35 had the highest, followed by WH59, then WH57. As shown by morphologic and microscopic examination, the proembryonic stage was best as explant material in terms of callus induction for $P$. koraiensis.

Good embryogenic callus is the basis for somatic embryo maturation. The coniferous embryogenic callus proliferates, usually with the PGRs concentration remaining constant or decreasing over time (Pullman and Bucalo 2011; Klimaszewska et al. 2016). Our results showed that embryogenic callus of $P$. koraiensis could proliferate over the long-term when NAA and 6-BA concentrations were reduced. Conifer species differ in which hormones are suitable for proliferation of, embryogenic callus. Although P. koraiensis proliferated better when 6-BA and KT were added in a previous study (Liu et al. 2010), our results showed that KT played a negative role in the maintenance of embryogenic callus and its proliferation.

The callus subculture cycle of coniferous species is generally 10-21 days, but it varies greatly among species (Klimaszewska et al. 2016). During callus maintainenance and proliferation, there may be problems such as too long a subculture cycle and too much accumulation of secondary metabolites. We showed that too short a culture cycle affects the proliferation efficiency of embryogenic callus and increased the cost; too long a culture cycle leads to poor growth of embryogenic callus and eventually loss of embryogenicity. Considering the growth rate and growth state of embryogenic callus, a proliferation subculture cycle of 13-15 d maintained a good growth state of embryogenic callus and ensured long proliferation efficiency. After several subcultures, the callus grew better.
Here, the embryogenic callus proliferated in all treatments; however, the callus did not remain embryogenic over the long-term on media containing IBA +6-BA, IBA + ABA, 6-BA $+\mathrm{KT}$, or 2,4-D + ABA. Moreover, callus readily browned in media with IBA + ABA and 2,4-D + ABA. Although the lack of 6-BA may be the cause of browning of embryogenic callus, ABA may be unfavorable for proliferation. In the 6-BA $+\mathrm{KT}$ combination medium, callus readily browned, which could be caused by the high content of cytokinin or the lack of auxin. With 2,4-D +6-BA, embryogenicity was maintained, and cells proliferated for a long time, with a proliferation rate second only to NAA + 6-BA; therefore, these two PGRs combinations hold promise for good maintenance and proliferation of Korean pine callus. In this study, efficient embryogenic callus induction and proliferation system of $P$. koraiensis was established, providing a foundation for the development of a somatic embryogenesis system.

Open Access This article is licensed under a Creative Commons Attribution 4.0 International License, which permits use, sharing, adaptation, distribution and reproduction in any medium or format, as long as you give appropriate credit to the original author(s) and the source, provide a link to the Creative Commons licence, and indicate if changes were made. The images or other third party material in this article are included in the article's Creative Commons licence, unless indicated otherwise in a credit line to the material. If material is not included in the article's Creative Commons licence and your intended use is not permitted by statutory regulation or exceeds the permitted use, you will need to obtain permission directly from the copyright holder. To view a copy of this licence, visit http://creativecommons.org/licenses/by/4.0/.

\section{References}

Ahn CH, Tull AR, Montello PM, Merkle SA (2017) A clonal propagation system for atlantic white cedar (chamaecyparis thyoides) via 
somatic embryogenesis without the use of plant growth regulators. Plant Cell Tissue Organ Cult 1:97-101

Cao Y, Shen HL, Li J (2009) Primary study on callus induction of Pinus koraiensis. For Sci Technol 34(3):1-4 (in Chinese)

Gao F, Shen HL, Liu CP, Wang Y, Zhang P, Yang L (2017) Culture condition optimization and explant selection for callus induction from mature embryo of Pinus koraiensis. J Nanjing For Univ (Nat Sci Ed) 41(03):43-50 (in Chinese)

Humánez A, Blasco M, Brisa C, Segura J, Arrillaga I (2013) Somatic embryogenesis from different tissues of spanish populations of maritime pine. Plant Cell Tissue Organ Cult 111(3):373-383

Klimaszewska K, Hargreaves C, Lelu-Walter MA, Trontin JF (2016) Advances in conifer somatic embryogenesis since year 2000. In vitro embryogenesis in higher plants. Springer, New York, pp 131-161

Lelu-Walter MA, Thompson D, Harvengt L, Sanchez L, Toribio M, Pâques LE (2013) Somatic embryogenesis in forestry with a focus on Europe: state-of-the-art, benefits, challenges and future direction. Tree Genet Genomes 9(4):883-899

Lelu-Walter MA, Gautier F, Eliášová Kateřina, Sanchez L, Teyssier C, Lomenech AM, Metté CL, Hargreaves C, Trontin JF, Reeves C (2018) High gellan gum concentration and secondary somatic embryogenesis: two key factors to improve somatic embryo development in pseudotsuga menziesii [mirb.]. Plant Cell Tissue Organ Cult 132(1):137-155

Liang Y, Shen HL, Liu CP, Yang L, Zhang P (2016) Comparison of methods for extracting high-throughput sequencing RNA from Korean pine seeds. J For Res 27(1):33-40

Liu BG, Li CH, Zhang HG (2010) Screning of influence factors on maintenance and proliferation of embryogenic callus of Picea koraiensis. J North East For Univ 7(38):56-60

Niskanen AM, Lu J, Seitz S, Keinonen K, Von Weissenberg K, Pappinen A (2004) Effect of parent genotype on somatic embryogenesis in scots pine (pinus sylvestris). Tree Physiol 24(11):1259-1265

Nunes S, Marum L, Farinha N, Pereira VT, Almeida T, Sousa D (2018) Somatic embryogenesis of hybrid pinus elliottii var. elliottii $\times$ p caribaea var. hondurensis and ploidy assessment of somatic plants. Plant Cell Tissue Organ Cult 132(1):71-84

Pullman GS, Bucalo K (2011) Pine somatic embryogenesis using zygotic embryos as explants. Methods Mol Biol 710(710):267-291
Salaj T, Matusova R, Salaj J (2015) Conifer somatic embryogenesis-an efficient plant regeneration system for theoretical studies and mass propagation. Dendrobiology 74:69-76

Santa-Catarina C, Silveira V, Guerra MP, Steiner N, Macedo AF, Floh EI (2012) The use of somatic embryogenesis for mass clonal propagation and biochemical and physiological studies in woody plants. New For 43(4):429-440

Shen XH, Jiang XN, Yill SP, Mahedrappa MK (2005) Somatic Embryogenisis (SE) in Korean pine (pinus. Koraiensis sieb. et zucc). J Chengdu Univ (Nat Sci) 24(1):11-14 (in Chinese)

Steiner N, Farias-Soares FL, Éder C, Schmidt Pereira MLT, Scheid B, Rogge-Renner GD (2016) Toward establishing a morphological and ultrastructural characterization of proembryogenic masses and early somatic embryos of araucaria angustifolia, (bert.) o. kuntze. Protoplasma 253(2):487-501

Tret'yakova IN, Shuvaev DN (2015) Somatic embryogenesis in pinus pumila and productivity of embryogenic lines during long-term cultivation in vitro. Russ J Dev Biol 46(5):276-285

Trontin JF, Aronen T, Hargreaves C, Montalbán IA, Klimaszewska $\mathrm{K}$ (2016) International effort to induce somatic embryogenesis in adult pine trees. Vegetative propagation of forest trees, pp 211-260

Wang Y, Zhao TT, Yang W (2015) Proper condition for callus induction from mature zygotic embryo explants of Pinus koraiensis. For Eng 2:5-7 (in Chinese)

Yang XY, Zhang XL (2010) Regulation of somatic embryogenesis in higher plants. Crit Rev Plant Sci 29(1):36-57

Zeng FC, Zhang XL, Cheng L, Hu LS, Zhu LF, Cao JL, Guo XP (2007) A draft gene regulatory network for cellular totipotency reprogramming during plant somatic embryogenesis. Genomics 90(5):620-628

Zuzana V, Kateřina E, Lucie F, Martin V (2011) The role of auxins in somatic embryogenesis of abies alba. Cent Eur J Biol 6(4):587-596

Publisher's Note Springer Nature remains neutral with regard to jurisdictional claims in published maps and institutional affiliations. 